\title{
RESPOSTAS MORFOLÓGICAS DE CULTIVARES DE ALFACE SOB DEFICIÊNCIA HÍDRICA
}

\author{
MORPHOLOGICAL RESPONSES OF LETTUCE CULTIVARS UNDER WATER \\ DEFICIENCY 8 \\ RESPUESTAS MORFOLÓGICAS DE LOS CULTIVARES DE LECHUGA BAJO \\ DEFICIENCIA DE AGUA \&
}

Recebido em: 17/09/2021 - Aprovado em: 07/10/2021 - Publicado em: 18/10/2021

http://dx.doi.org/10.18011/bioeng2021v15n3p351-366

Sidney Antônio Urbano Júnior ${ }^{1}$ (sidneimgl@gmail.com)

Sebastião Soares de Oliveira Neto' (neto.soliver@gmail.com)

\footnotetext{
${ }^{1}$ Faculdades Integradas de Bauru. Bauru, SÃO PAULO, Brasil.
}

\section{RESUMO}

A alface é a principal folhosa consumida no Brasil. A deficiência hídrica é um dos principais redutores de produtividade das culturas, atingindo diversas áreas no planeta. Embora o cultivo de alface seja quase que totalmente realizado em áreas irrigadas, se por algum motivo faltar água para as plantas, diversos danos podem ser observados na cultura. $O$ objetivo do trabalho foi avaliar cultivares de alface e verificar 0 desempenho agronômico e os efeitos da deficiência hídrica moderada nas características morfológicas da cultura. $\mathrm{O}$ experimento foi realizado em blocos casualizados em esquema fatorial, sendo testada quatro cultivares (Jade, Vanda, Loreane e Valentina) e as condições com e sem deficiência hídrica. As cultivares Loreane e Valentina apresentaram resultados superiores de comprimento de parte aérea e massa seca de parte aérea, enquanto a cultivar Jade apresentou maior número de folhas e portanto podem tolerar deficiência hídrica moderada nas fases iniciais da cultura.

Palavras-chave: Horticultura. Estresses abióticos. Olerícolas. Seca. 


\section{INTRODUÇÃO}

A cultura da alface (Lactuca sativa L.) é a folhosa mais consumida no Brasil, sendo que nos últimos anos a produção e consumo cresceram de forma expressiva (IBGE, 2017). O alface é de fundamental para a economia brasileira, movimentando bilhões de reais no varejo (BRAINER, 2019), e é cultivada por agricultores familiares, o que the confere grande importância econômica e social, além de ser um fator de fixação do homem ao campo (VILLAS BÔAS et al., 2004; SILVA et al., 2017).

A produção agrícola mundial é afetada por fenômenos climáticos adversos, tais como, alterações na temperatura, pluviosidade, umidade do solo, radiação solar, dentre outros. Dentre os principais fatores abióticos que interferem na produção das culturas, o déficit hídrico é o mais importante, e ocorre quando a perda de água pela planta excede a capacidade de absorção pela raiz, provocando danos ao crescimento e desenvolvimento (BRITO et al., 2015; FERNANDES et al., 2015).

Dentre os efeitos ocasionados pela deficiência hídrica na célula vegetal está à desidratação, redução do potencial hídrico e da resistência hidráulica nos vasos do xilema. Os efeitos da seca ainda resultam em prejuízos na expansão foliar, atividades celulares e metabólicas; fechamento estomático; inibição fotossintética; abscisão foliar, cessando o crescimento da planta (TAIZ et al., 2017). São prejudicadas a expansão e a divisão celular, proporcionando a diminuição do crescimento das folhas e do caule (DUARTE, 2012).

Os fatores climáticos adversos, como temperatura e luminosidade podem interferir de forma negativa no desenvolvimento da planta, sendo de fundamental importância o controle desses fatores e o uso de técnicas como ambiente protegido ajuda na busca por melhores resultados (SANTOS et al., 2010). A associação da técnica com o manejo criterioso da irrigação contribui com o aumento na produtividade de diversas hortaliças bem como na melhoria da qualidade do produto (ZENG et al., 2009; BILIBIO et al., 2010). No entanto qualquer descuido na quantidade de água disponível para as plantas pode gerar impactos negativos na produtividade.

Com base neste exposto, o objetivo do trabalho foi avaliar quatro cultivares modernas de alface, com o intuito de verificar o desempenho agronômico e os efeitos da deficiência hídrica moderada nas características morfológicas da cultura e indicar aquelas que possuem tolerância à seca nas fases iniciais da cultura. 


\subsection{DESCRIÇÃO DO EXPERIMENTO}

O experimento foi conduzido em ambiente protegido em área experimental própria, no município de Arealva, Estado de São Paulo.

Foi avaliado o comportamento de quatro cultivares de alface (Vanda, Jade, Loreane e Valentina) submetidas a dois regimes hídricos (30\% e 100\% de água disponível), que representam respectivamente as condições com e sem o efeito do déficit hídrico.

Para a determinação da capacidade de retenção de água, antes do transplante das mudas, os recipientes plásticos foram pesados cheios de solo, saturados com água e após uma hora pesados novamente. Com base na capacidade de retenção de água, foram calculados os volumes de 30\% e 100\% de água disponível.

O delineamento experimental utilizado foi o de blocos casualizados em esquema fatorial (Fator 1: estresse hídrico; Fator 2: cultivar), com dez repetições.

As mudas foram adquiridas de fornecedor e transplantadas para um recipiente plástico de $300 \mathrm{~mL}$ em 13 de setembro de 2019. O solo utilizado foi possui a seguinte composição: areia (50\%), argila (30\%), silte (20\%), com histórico de cultivo de hortaliças e grãos.

A deficiência hídrica iniciou-se imediatamente após o plantio das mudas, sendo mantido por todo período do experimento. A irrigação foi realizada diariamente com o auxílio de uma seringa, colocando-se a água na quantidade exata para manter o solo em 30\% ou $100 \%$ de água disponível. O controle da deficiência hídrica foi realizada através da pesagem por balança de precisão.

\subsection{CARACTERÍSTICAS AVALIADAS}

Aos 15 dias após o transplante das mudas (DAT), as plantas foram retiradas do solo e então lavadas em água corrente e mensurados os seguintes caracteres: Número de folhas (NF): determinada através de contagem da quantidade de folhas de cada planta; Comprimento de parte aérea (CPA): obtida através da medição em régua graduada da parte área, medida dada em centímetros; Massa fresca da parte aérea (MFPA): realizada em balança de precisão $(0,000 \mathrm{~g})$, dada em gramas; Comprimento de raiz $(\mathrm{CR})$ : realizada 
através da medição da raiz em régua graduada, medida dada em centímetros; Massa fresca da raiz (MFR): realizada em balança de precisão $(0,000 \mathrm{~g})$, dada em gramas; Em seguida as plantas foram submetidas à secagem em estufa térmica de ventilação forçada, a $70^{\circ} \mathrm{C}$, para a determinação de massa seca de parte aérea (MSPA) e massa seca de raiz (MSR). A determinação foi realizada após três dias, através de pesagem em balança de precisão $(0,000 \mathrm{~g})$.

Os dados foram submetidos à análise de variância e teste de LSD à $5 \%$ de probabilidade pelo software Agrostat ${ }^{\oplus} \mathrm{e}$ à análise de componentes principais pelo software Minitab $17^{\circledR}$.

\section{RESULTADOS E DISCUSSÃO}

Os resultados do experimento demonstraram que a deficiência hídrica afeta os caracteres morfológicos na cultura do alface. A análise de variância indicou diferenças significativas entre as cultivares para a maioria das características avaliadas, exceto CPA e CR (Tabela 1).

Para o tratamento deficiência hídrica foram constatadas diferenças entre as condições com e sem deficiência hídrica para as variáveis NF, CPA, MFR e MSR. Foram observadas interações entre os tratamentos para as características MFPA, MFR e MSPA. Foram observados valores de coeficiente de variação entre 9,93\% (CPA) a 32,50\% (MSR). As médias individuais e gerais podem ser verificadas na Tabela 1. 
Tabela 1 - Médias e análise de variância das características avaliadas em quatro cultivares de alface submetidas à deficiência hídrica.

\begin{tabular}{|c|c|c|c|c|c|c|c|}
\hline Tratamento & NF & CPA (cm) & CR (cm) & MFPA (g) & MFR (g) & MSPA (g) & MSR (g) \\
\hline \multicolumn{8}{|l|}{ Cultivar } \\
\hline Vanda & 5,05 & 11,60 & 11,91 & 4,06 & 3,5130 & 0,1033 & 0,1772 \\
\hline Jade & 5,70 & 11,27 & 10,64 & 4,46 & 3,7130 & 0,1437 & 0,1828 \\
\hline Loreane & 4,65 & 11,78 & 10,78 & 2,89 & 3,0580 & 0,1219 & 0,1402 \\
\hline Valentina & 5,00 & 11,32 & 11,34 & 3,61 & 2,3880 & 0,0996 & 0,1458 \\
\hline \multicolumn{8}{|l|}{ Deficiência hídrica } \\
\hline Sem & 5,37 & 12,07 & 11,20 & 3,6755 & 2,6380 & 0,1176 & 0,1451 \\
\hline Com & 4,82 & 10,92 & 11,14 & 3,8377 & 3,6980 & 0,1166 & 0,1778 \\
\hline ANOVA & \multicolumn{7}{|c|}{ Quadrado médio } \\
\hline Cultivar (C) & $3,83^{\star \star}$ & $1,16^{\text {ns }}$ & $6,68^{\text {ns }}$ & $9,12^{* *}$ & $6,91^{\star \star}$ & $0,01^{\star *}$ & $0,01^{\star *}$ \\
\hline Deficiência hídrica $(\mathrm{DH})$ & $6,05^{* *}$ & $26,45^{\star *}$ & $0,09^{n s}$ & $0,53^{\text {ns }}$ & $22,47^{\star *}$ & $0,00^{\text {ns }}$ & $0,02^{* *}$ \\
\hline $\mathrm{C} \times \mathrm{DH}$ & $1,28^{\text {ns }}$ & $3,22^{\text {ns }}$ & $1,50^{\text {ns }}$ & $15,94^{\star *}$ & $12,39^{* *}$ & $0,03^{\star \star}$ & $0,00^{\text {ns }}$ \\
\hline Média geral & 5,10 & 11,49 & 11,17 & 3,7566 & 3,1680 & 0,1171 & 0,16 \\
\hline Desvio padrão & 0,90 & 1,14 & 1,59 & 0,73 & 0,95 & 0,03 & 0,05 \\
\hline CV\% & 17,47 & 9,93 & 14,23 & 19,42 & 29,99 & 27,00 & 32,50 \\
\hline
\end{tabular}

NF: número de folhas; CPA: comprimento de parte aérea; CR: comprimento de raiz; MFPA: massa fresca de parte aérea; MFR: massa fresca de raiz; MSPA: massa seca de parte aérea; MSR: massa seca de raiz; ** significativo ao nível de 0,01 de probabilidade; ns não significante.

Fonte: Os autores, 2021.

A redução nos parâmetros de crescimento vegetal é observada sob condições de restrição hídrica, pois são os primeiros afetados pela moderada deficiência hídrica; isso ocorre devido à diminuição da expansão e da divisão celular, proporcionando a diminuição do crescimento antes do estresse hídrico tornar-se severo a ponto de causar o fechamento dos estômatos e uma diminuição na fotossíntese (DUARTE, 2012).

As cultivares apresentaram diferentes respostas para número de folhas, sendo que a cultivar Jade teve uma média maior $(5,7)$ de produção de folhas que as demais (Figura 1). De acordo com Mota et al. (2001), o número de folhas por planta da alface é uma variável importante, já que o consumidor faz a aquisição do produto por unidade e não por peso.

A deficiência hídrica afetou a produção de folhas de alface. Nas condições sem deficiência hídrica foram observadas uma produção de folhas $11,4 \%$ maior que nas condições com deficiência hídrica (Figura 1). Fátima et al. (2018), verificaram os mesmos resultados para o crescimento inicial e tardio de alface sob estresse hídrico.

O comprimento de parte área foi afetado pela deficiência hídrica, sendo observada uma redução de 10,24 \% em condições estressantes (Figura 2).

A redução no crescimento em número de folhas e em altura de planta ocasionado pela deficiência hídrica está relacionada com a diminuição do turgor celular, que afeta a divisão e expansão celular, causando mudanças na anatomia, fisiologia e bioquímica das plantas (RODRIGUES et al., 2017; PELOSO et al., 2017). 
Figura 1 - Número de folhas de alface sob deficiência hídrica.

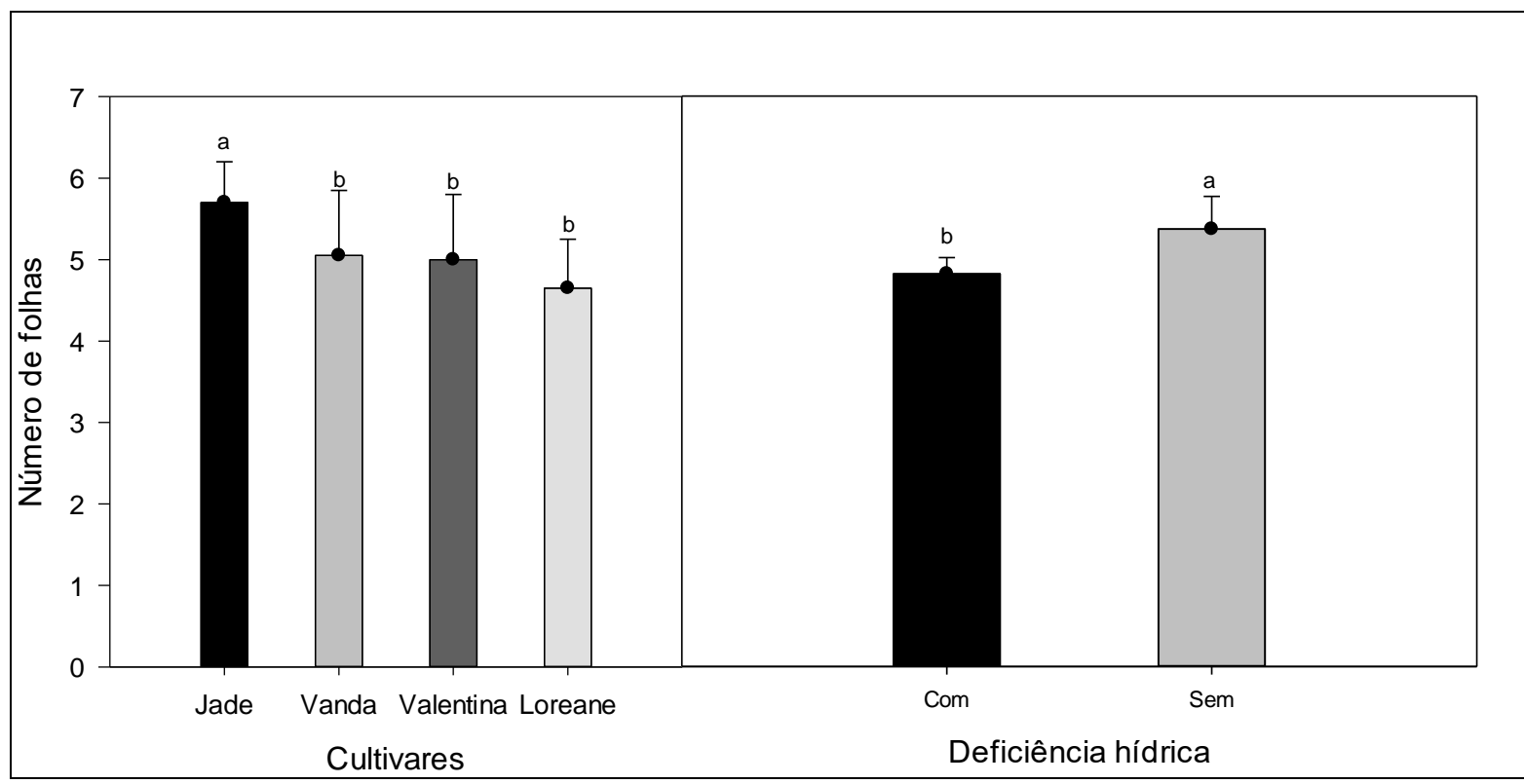

Fonte: Os autores, 2021.

Figura 2 - Comprimento de parte aérea de alface sob deficiência hídrica.

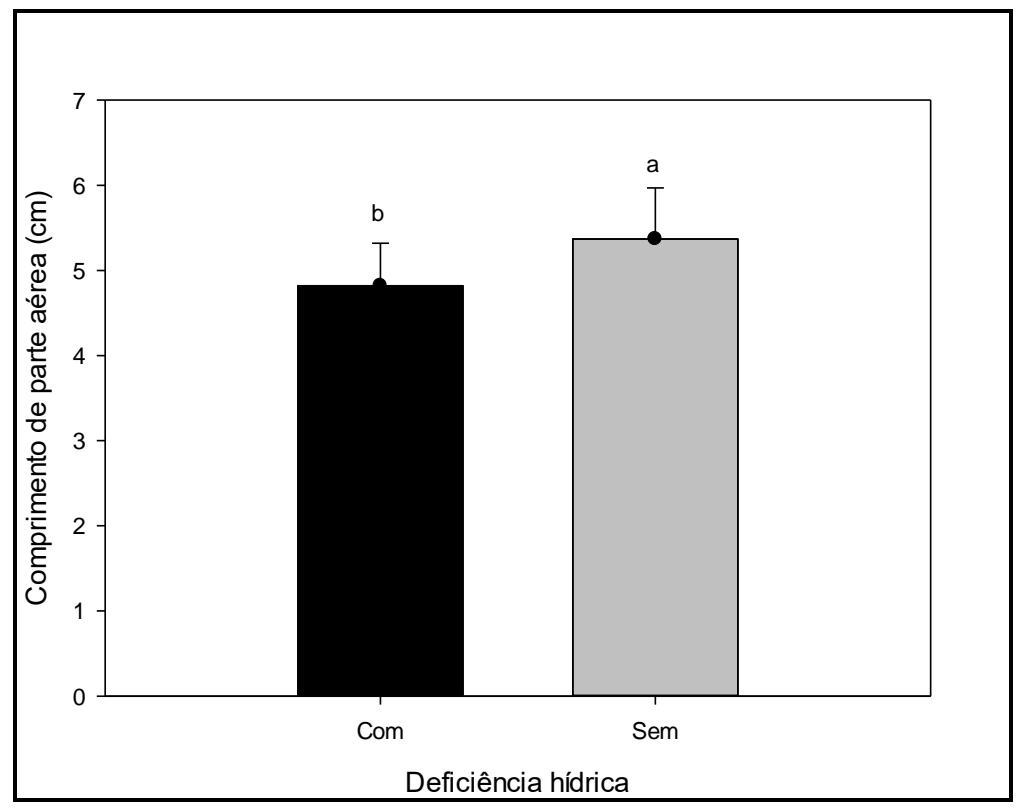

Fonte: Os autores, 2021.

Para comprimento de raiz (Figura 3), observou-se diferenças entre as cultivares, sendo que a cultivar Vanda apresentou a maior média de comprimento de raiz $(11,91 \mathrm{~cm})$. 
Figura 3 - Comprimento de raiz de alface sob deficiência hídrica.

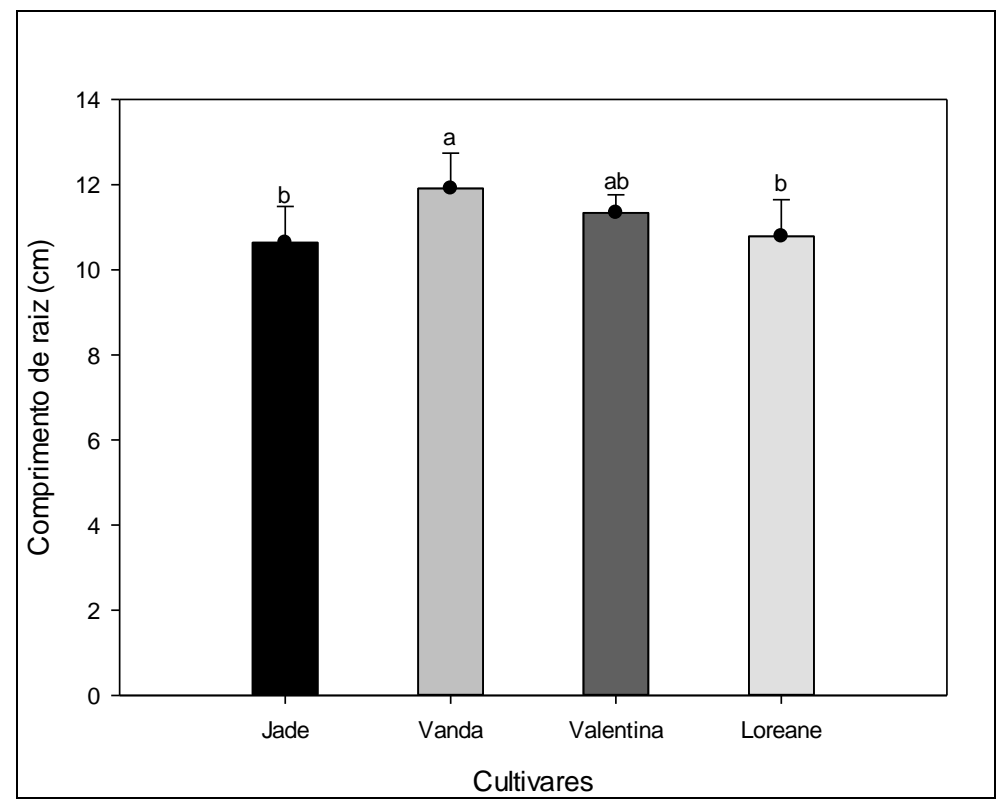

Fonte: Os autores, 2021.

A massa fresca de parte aérea foi afetada pela deficiência hídrica nas cultivares Jade e Vanda, enquanto verificou-se um elevado incremento de massa fresca na parte aérea da cultivar Loreane (Figura 4). Os genótipos podem ter diferentes comportamento quando submetidos à algum tipo de estresse abiótico (CRUZ \& CARNEIRO, 2004). Essa diferença está na base genética e no trabalho de seleção realizado pela empresa de melhoramento que desenvolveu o material.

Em condições de deficiência hídrica, a cultivar Jade se destacou, produzindo elevada massa fresca de parte aérea $(4,4130 \mathrm{~g})$. Já em condições sem deficiência hídrica, a cultivar Vanda produziu a maior média de massa fresca $(5,0130 \mathrm{~g})$.

Esses resultados podem ser explicados embasando-se no trabalho de Flecha (2004), que expõe que o excesso de umidade disponível pode provocar redução no peso da parte área. 
Figura 4 - Massa fresca de parte aérea de alface sob deficiência hídrica.

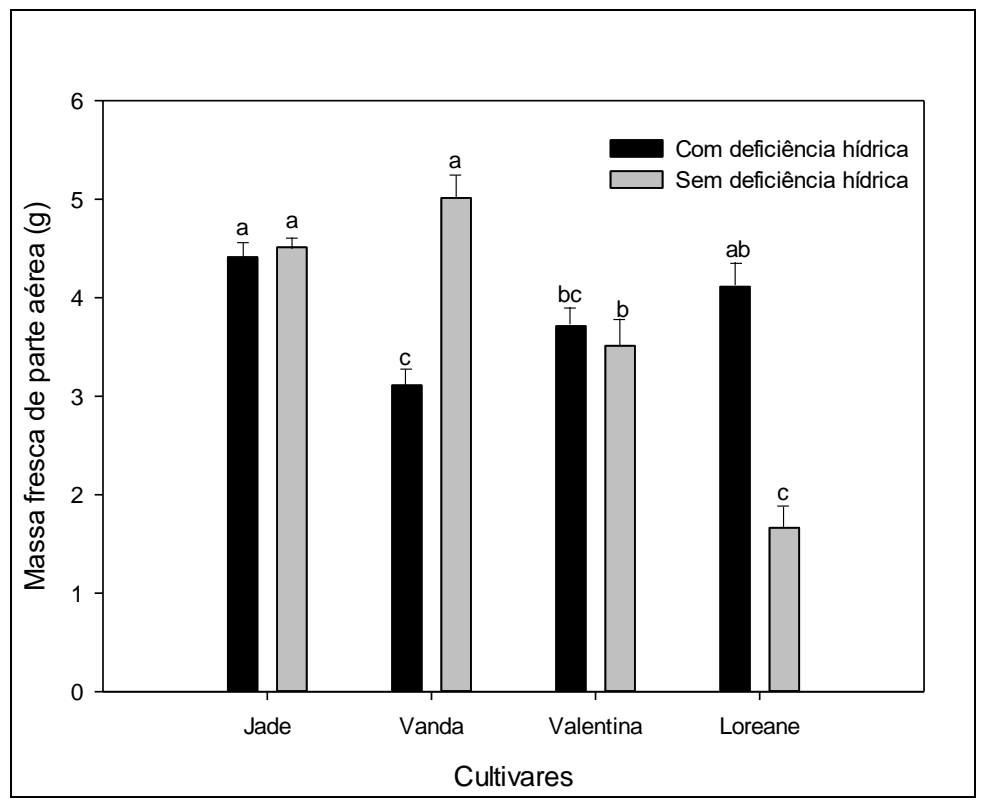

Fonte: Os autores, 2021.

A deficiência hídrica afetou a resposta para massa seca de parte aérea da maioria das cultivares avaliadas, exceto a cultivar Valentina que apresentou elevada massa seca de parte aérea mesmo em condições de seca (Figura 5). Fátima et al. (2019), também verificou que lâmina de irrigação de $100 \%$ de água disponível proporcionou maior crescimento das plantas de alface em relação as plantas irrigadas com lâminas menores.

O decréscimo de água disponível diminui o potencial de água na folha e sua condutância estomática, resultando no fechamento dos estômatos, isso faz com que haja um bloqueia no fluxo de gás carbônico para as folhas, e diminui o acúmulo de fotoassimilados (PAIVA et al., 2005).

Anjum et al. (2017) e Todaka et al. (2017), indicam ainda que as características morfofisiológicas e bioquímicas relacionadas ao estresse hídrico incluem alterações no desenvolvimento foliar e no acúmulo de fotoassimilados. 
Figura 5 - Massa seca de parte aérea de alface sob deficiência hídrica.

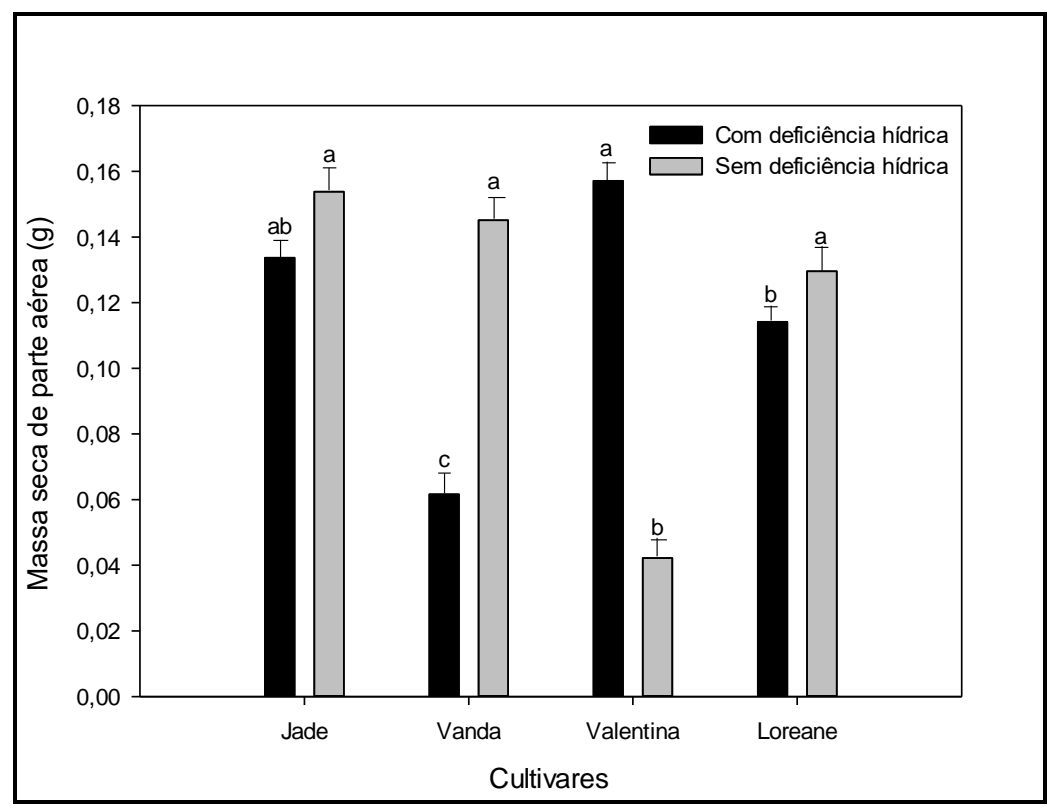

Fonte: Os autores, 2021.

Para massa fresca de raiz (Figura 6), na condição de deficiência hídrica foram observadas maiores médias em comparação com a condição sem deficiência hídrica, sendo que cultivar Loreane apresentou a maior média do experimento na condição de deficiência hídrica $(4,7030 \mathrm{~g})$.

Para diversas espécies, vários estudos documentam que, sob deficiência hídrica, há um maior investimento no desenvolvimento das raízes, resultando em aumento de comprimento (FITTER \& HAY, 1987) e de matéria seca da raiz (PEREIRA \& PALLARDI, 1989).

A cultivar Jade destacou-se produzindo elevada massa de matéria seca de raiz $(0,1828 \mathrm{~g})$. A deficiência hídrica provocou um aumento na massa seca de raiz de alface (Figura 7), sendo observados valores de $0,1780 \mathrm{~g}$ em condições de deficiência hídrica, enquanto em condições normais de cultivo, observou-se valores de $0,1451 \mathrm{~g}$.

Nossos resultados corroboram com Magalhães et al. (2015) e Santana et al. (2019), em trabalhos avaliando o desenvolvimento da cultura do alface sob diversas condições hídricas, verificaram que não houve diferença estatística entre os tratamentos para diversas variáveis, como massa fresca e seca de parte aérea e massa fresca e seca de raiz. 
Figura 6 - Massa fresca de raiz de alface sob deficiência hídrica.

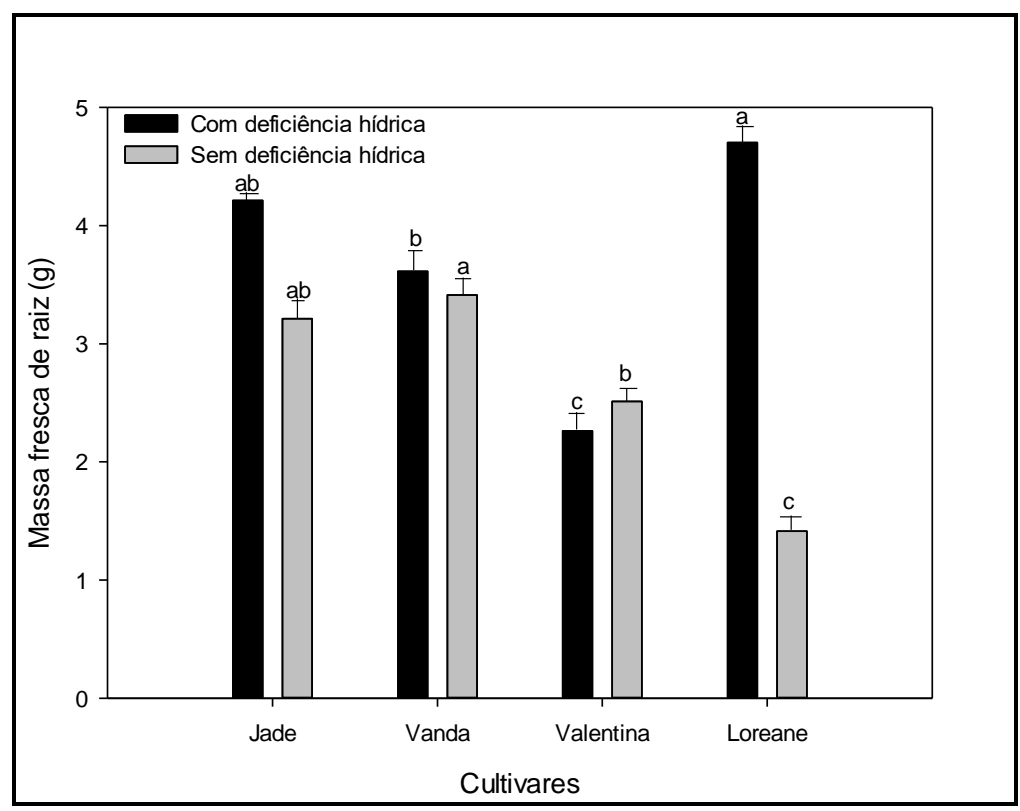

Fonte: Os autores, 2021.

Figura 7 - Massa seca de raiz de alface sob deficiência hídrica.

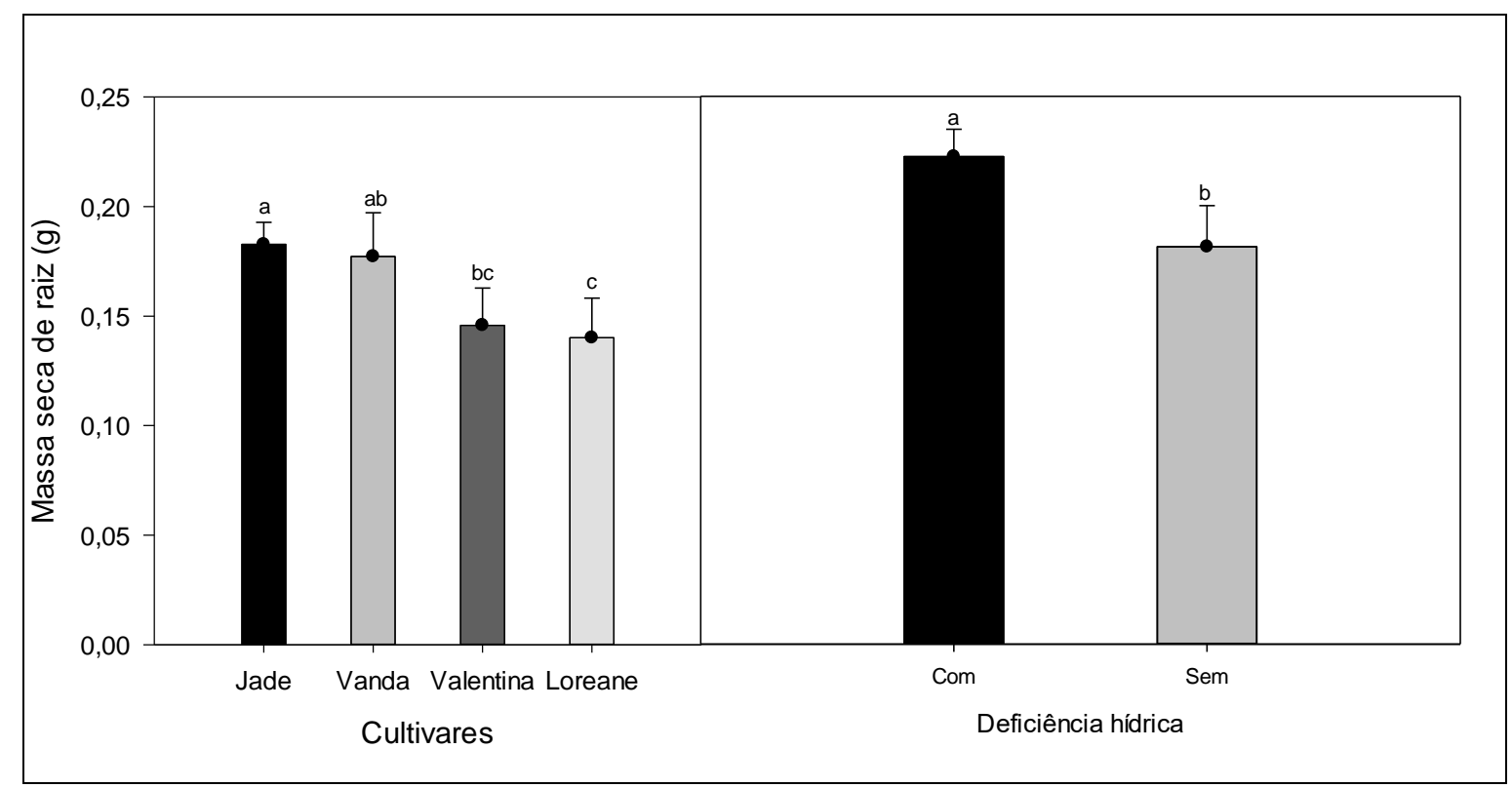

Fonte: Os autores, 2021.

Pensando nas características comerciais desejáveis na cultura do alface, foi realizada a análise de componentes principais (Tabela 2, Figura 8). Os maiores autovetores observados para CP1 foram 0,619 e -0,4370 para as variáveis número de folhas e comprimento de parte aérea. Já para CP2, os autovetores representativos foram aqueles 
que explicaram a resposta das variáveis comprimento de raiz $(0,702)$ e massa seca de parte aérea $(-0,544)$ (Tabela 2). As cultivares associadas a esses autovetores são consideradas as de melhores caracteres comerciais e agronômicos.

De acordo com a Figura 8, as cultivares Loreane e Valentina apresentaram resultados superiores de comprimento de parte aérea e massa seca de parte aérea, enquanto a cultivar Jade apresentou maior número de folhas.

Tabela 2 - Componentes principais, autovalores $(\lambda)$ e porcentagem da variância explicada pelos componentes (\%VCP) nos caracteres de importância comercial avaliados em alface sob deficiência hídrica.

\begin{tabular}{lccc}
\hline Componente principal & $\boldsymbol{\lambda}$ & \% VCP & \%VCP (acumulada) \\
\hline CP1 & 2,5965 & 0,519 & 0,519 \\
CP2 & 1,9265 & 0,385 & 0,905 \\
CP3 & 0,4770 & 0,095 & 1,000 \\
\hline Variáveis & & CP1 & CP2 \\
Número de folhas & 0,619 & $-0,039$ \\
Comprimento de parte aérea $(\mathrm{cm})$ & $-0,437$ & $-0,435$ \\
Massa seca de parte aérea $(\mathrm{g})$ & 0,339 & $-0,544$ \\
Comprimento de raiz $(\mathrm{cm})$ & & 0,135 & 0,702 \\
\hline
\end{tabular}

Figura 8 - Análise de componentes principais para características avaliadas em alface sob deficiência hídrica.

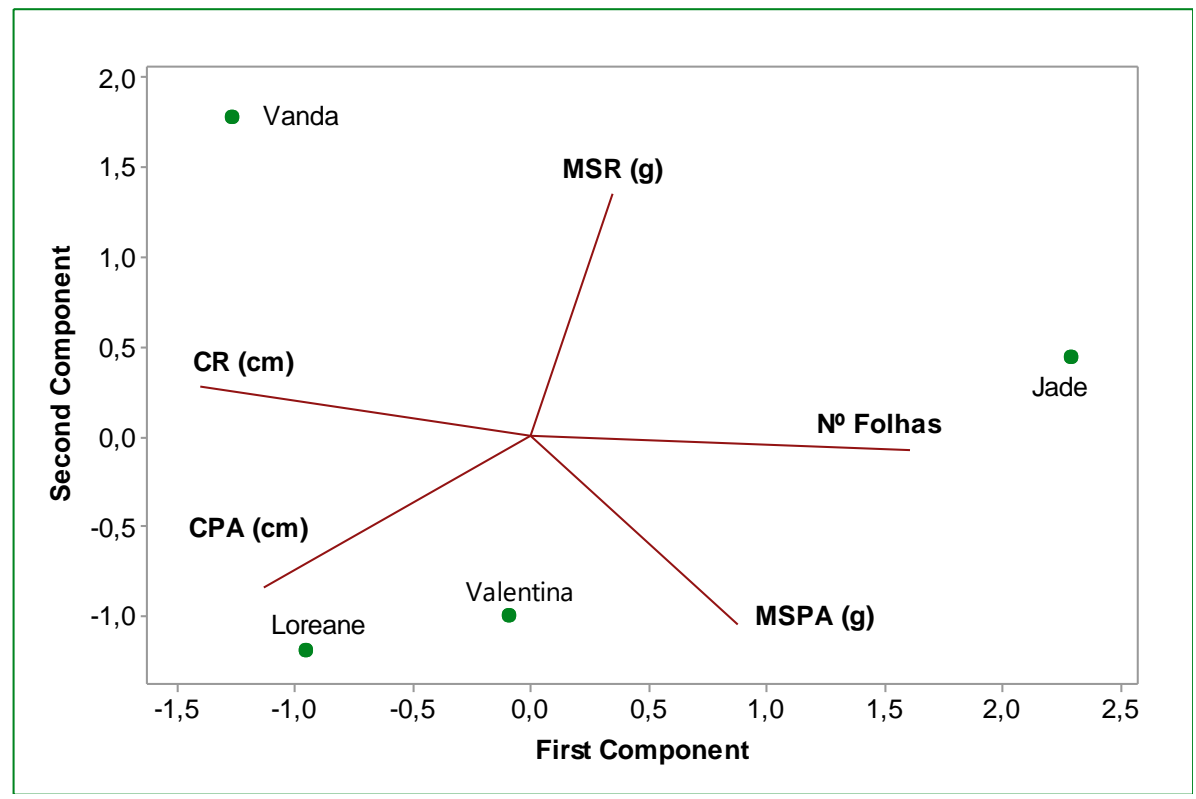

Fonte: Os autores, 2021. 


\section{CONCLUSÕES}

A deficiência hídrica influenciou a respostas das características morfológicas nas quatro cultivares de alface avaliadas. A seca moderada nos primeiros dias de desenvolvimento da alface diminuiu o número de folhas e o comprimento de parte aérea e de raiz, e provocou um aumento na massa fresca e seca de raízes.

As cultivares Loreane e Valentina apresentaram resultados superiores de comprimento de parte aérea e massa seca de parte aérea, enquanto a cultivar Jade apresentou maior número de folhas e, portanto, podem tolerar deficiência hídrica moderada nas fases iniciais da cultura.

\section{REFERÊNCIAS}

ANJUM, S. A. et al. Growth and developmental responses of crop plants under drought stress: a review. Zemdirbyste-Agriculture, Kèdainiai, Lituânia, v. 104, n. 3, p. 267-276, 2017. DOI: 10.13080/z-a.2017.104.034.

BILIBIO, C. et al. Desenvolvimento vegetativo e produtivo da berinjela submetida a diferentes tensões de água no solo. Revista Brasileira de Engenharia Agrícola e Ambiental, Campina Grande, Paraíba, Brasil, v. 14, p. 730-735, 2010.

DOI:10.1590/S1415-43662010000700007.

BRAINER, M. S. C. P. Informe setorial de hortaliças. Caderno Setorial ETENE. Fortaleza: Banco do Nordeste, 2019.

BRITO, M.E.B. et al. Comportamento fisiológico de combinações copa/porta enxerto de citros sob estresse hídrico. Revista Brasileira de Ciências Agrárias, Recife, Pernambuco, Brasil, v. 7, p.857- 865, 2015. DOI: 10.5039/agraria.v7isa1941.

CRUZ, C. D.; CARNEIRO, P. C. S. Modelos biométricos aplicados ao melhoramento genético. Viçosa: UFV, 2006.

DUARTE, A. L. M. Efeito da água sobre o crescimento e o valor nutritivo das plantas forrageiras. Pesquisa \& Tecnologia, Campinas, São Paulo, Brasil, v. 9, n. 2, p.1-6, 2012.

FERNANDES, F. B. P. et al. Efeito de manejos do solo no déficit hídrico, trocas gasosas e rendimento do feijão-de-corda no semiárido. Revista Ciência Agronômica, Fortaleza, Ceará, Brasil, v. 46, n. 3, 2015. DOI: 10.5935/1806-6690.20150032.

FATIMA, R. T. et al. Crescimento e trocas gasosas em alface cultivada sob regimes hídricos e adubação fosfatada. Revista Brasileira de Agricultura Irrigada, Fortaleza, Ceará, Brasil, v. 12, n. 3, p. 2683-2691, 2018. DOI: 10.7127/rbai.v12n300854. 
FATIMA, R. T. et al. Adubação silicatada como atenuante do estresse hídrico no crescimento e trocas gasosas do alface. Revista Engenharia na Agricultura Reveng, Viçosa, Minas Gerais, Brasil, v. 27, n. 2, p. 170-178, 2019. DOI: 10.13083/reveng.v27i2.892.

FITTER, A.H.; HAY, R. K. M. Environmental Physiology of Plants. USA: Academic Press. 1987.

FLECHA, P. A. N. Sensibilidade das culturas da batata (Solanun tuberosus L.) e da alface (Lactuca sativa L.) ao excesso de água no solo. 2004. 68p. Dissertação (Mestrado). Programa de Pós-Graduação em Fitotecnia. Universidade de São Paulo, Piracicaba, 2004.

INSTITUTO BRASILEIRO DE GEOGRAFIA E ESTATÍSTICA - IBGE. Censo agropecuário. Disponível em: <https://censos.ibge.gov.br/agro/2017/> Acesso em: 15/09/2021.

MOTA, J. H. et al. Efeito do cloreto de potássio via fertirrigação na produção de alface americana em cultivo protegido. Ciência e Agrotecnologia, Lavras, Minas Gerais, Brasil, v. 25, n. 3, p. 542-549, 2001.

NASCIMENTO, M. V. et al. Manejo da adubação nitrogenada nas culturas de alface, repolho e salsa. Revista de Agricultura Neotropical, Cassilândia, Mato Grosso do Sul, Brasil, v. 4, n. 1, p. 65-71, 2017. DOI: 10.32404/rean.v4i1.

PAIVA, A. S.; FERNANDES, E. J.; RODRIGUES, T. J. D.; TURCO, J. E. P. Condutância estomática em folhas de feijoeiro submetido a diferentes regimes de irrigação. Revista de Engenharia Agrícola, Jaboticabal, São Paulo, Brasil, v. 25, p. 161-169, 2005. DOI: 10.1590/S0100-69162005000100018.

PELOSO, A. F.; TATAGIBA, S. D.; AMARAL, J. F. T. Limitações do crescimento vegetativo em cafeeiro arábica promovido pelo déficit hídrico. Revista Engenharia na Agricultura, Viçosa, Minas Gerais, Brasil, v. 25, n. 2, p. 139-147, 2017. DOI:

10.13083/reveng.v25i2.755.

PEREIRA, J. S.; PALLARDI, S. Water stress limitation to tree productivity. In: PEREIRA, J.S.; LANDSBERG, J. J. Biomass production by fast growing trees. London: Kluwer Academic, 1989. p. 37-56.

RODRIGUES, J. D. B. et al. Comportamento morfológico no período de crescimento de progênies de cupuaçuzeiro em resposta a restrição hídrica. Ciência \& Tecnologia, Jaboticabal, São Paulo, Brasil, v. 9, p. 1-6, 2017.

SANTANA, J. S. et al. Resposta de cultivares de alface sob diferentes lâminas de irrigação e doses de nitrogênio. Enciclopédia Biosfera, Goiânia, Goiás, Brasil, v. 16, n. 29, p. 1332-1346, 2019. DOI: 10.18677/EnciBio_2019A120.

SANTOS, L. L. et al. Luminosidade, temperatura do ar e do solo em ambientes de cultivo protegido. Revista de Ciências Agro-Ambientais, Alta Floresta, Mato Grosso, Brasil, v. 8, n. 1, p. 83- 93, 2010. 
SILVA, A. C.; DA SILVA, V. S. G.; MANTOVANELLI, B. C.; SANTOS, G. M. Formação de mudas de alface em diferentes bandejas e substratos. Revista da Universidade Vale do Rio Verde, Betim, Minas Gerais, Brasil, v. 15, n. 1, p. 465-471, 2017. DOI: http://dx.doi.org/10.5892/ruvrd.v15i1.3011.

TAIZ, L.; ZEIGER, E.; MOLLER, I. M.; MURPHY, A. Fisiologia e desenvolvimento vegetal. Porto Alegre: Artmed, 2017.

TODAKA, D. et al. Temporal and spatial changes in gene expression, metabolite accumulation and phytohormone content in rice seedlings grown under drought stress conditions. The Plant Journal, Hoboken, Nova Jersey, EUA, v. 90, p. 61-78, 2017. DOI: 10.1111/tpj.13468.

VILLAS BÔAS, R. L., et al. Efeito de doses e tipos de compostos orgânicos na produção de alface em dois solos sob ambiente protegido. Horticultura Brasileira, Vitoria da Conquista, Bahia, Brasil, v. 22, n. 1, p. 28-34, 2004. DOI: 10.1590/S010205362004000100006.

ZENG, C.; BIE, Z.; YUAN, B. Determination of optimum irrigation water amount for dripirrigated muskmelon (Cucumis melo L.) in plastic greenhouse. Agricultural Water Management, v. 96, n. 4, p.595-602, 2009. DOI: 10.1016/j.agwat.2008.09.019. 


\begin{abstract}
Lettuce is the main hardwood consumed in Brazil. Water deficit is one of the main crop productivity reducers, affecting several areas of the planet. Although the cultivation of lettuce is almost entirely carried out in irrigated areas, if for some reason there is a lack of water for the plants, several damages can be observed in the crop. The objective of this work was to evaluate lettuce cultivars and verify the agronomic performance and the effects of moderate water deficit on the morphological traits of the crop. The experiment was carried out in randomized blocks in a factorial scheme, being tested four cultivars (Jade, Vanda, Loreane, and Valentina) and the conditions with and without water deficit. Cultivars Loreane and Valentina showed superior results for shoot length and shoot dry mass, while cultivar Jade showed higher number of leaves and therefore can tolerate moderate water deficit in the early stages of the crop.
\end{abstract}

Keywords: Horticulture. Abiotic stresses. Vegetables. Dry.

\title{
RESUMEN
}

La lechuga es la principal madera dura consumida en Brasil. El déficit hídrico es uno de los principales reductores de la productividad de los cultivos y afecta a varias zonas del planeta. Aunque el cultivo de la lechuga se realiza casi en su totalidad en zonas de regadío, si por alguna razón falta agua para las plantas, se pueden observar varios daños en el cultivo. El objetivo de este trabajo fue evaluar cultivares de lechuga y verificar el comportamiento agronómico y los efectos del déficit hídrico moderado sobre las características morfológicas del cultivo. El experimento se realizó en bloques al azar en un esquema factorial, probándose cuatro cultivares (Jade, Vanda, Loreane y Valentina) y las condiciones con y sin déficit hídrico. Los cultivares Loreane y Valentina mostraron resultados superiores en longitud de brote y masa seca de brotes, mientras que el cultivar Jade mostró mayor número de hojas y por lo tanto puede tolerar un déficit hídrico moderado en las primeras etapas del cultivo.

Palabras-clave: Horticultura. Estreses abióticos. Verduras. Seco. 


\section{LICENÇA DE USO}

Este é um artigo publicado em acesso aberto (Open Access) sob a licença Creative Commons Atribuição 4.0 Internacional (CC BY 4.0), que permite uso, distribuição e reprodução em qualquer meio, desde que o trabalho original seja corretamente citado. Mais informações em: http://creativecommons.org/licenses/by/4.0

\section{CONFLITO DE INTERESSES}

Os autores declaram que não há conflito de interesses neste trabalho.

\section{CONTRIBUIÇÕES AUTORAIS}

Autor 1: execução dos experimentos, análise de dados, escrita.

Autor 2: execução dos experimentos, análise de dados, escrita do manuscrito, revisão, orientação.

\section{FINANCIAMENTO}

O presente trabalho não contou com apoio financeiro.

\section{COMO REFERENCIAR}

URBANO JÚNIOR, Sidney Antônio; OLIVEIRA NETO, Sebastião Soares de. Respostas morfológicas de cultivares de alface sob deficiência hídrica. Revista Brasileira de Engenharia de Biossistemas (Tupã), v. 15, n. 3, p. 351-366, 2021. DOI:

http://dx.doi.org/10.18011/bioeng2021v15n3p351-366.

\section{RESPONSABILIBADE EDITORIAL}

Prof. Dr. Fernando Ferrari Putti ${ }^{1}$, Prof. Dr. Paulo Sérgio Barbosa dos Santos ${ }^{1}$, Prof. Dr. Eduardo Festozo Vicente ${ }^{1}$ e Prof. Dr. Diogo de Lucca Sartori ${ }^{1}$

1 Universidade Estadual Paulista "Júlio de Mesquita Filho", FCE - Faculdade de Ciências e Engenharia, Tupã, SP, Brasil. 